\title{
Variation in attachment of the barnacle Balanus amphitrite: sensation or something else?
}

\author{
Eric R. Holm, Marion McClary Jr, Daniel Rittschof* \\ Duke University Marine Laboratory, Beaufort, North Carolina 28516, USA
}

\begin{abstract}
Settlement, attachment, and metamorphosis of larvae of marine invertebrates is extremely variable in the laboratory and in nature. The relative contributions of genetic, ontogenetic and environmental effects to this variation are not well understood. We tested for genetic, maternal and ontogenetic effects on permanent attachment of cyprids of the barnacle Balanus amphitrite (Darwin). Larvae were assayed for attachment in response to a control treatment and 3 artificial inducers: 20-hydroxyecdysone (20-HE), 3-isobutyl-1-methylxanthine (IBMX), and phorbol 12,13dibutyrate (PDB). We observed strong family effects on attachment in the control, 20-HE, and IBMX treatments, suggesting that attachment in response to these treatments is influenced by genetic or maternal factors. In addition, attachment responses were correlated, indicating that the same genetic or maternal factors may affect attachment in each treatment. Family effects on attachment in the control treatments decreased with cypris age, suggesting the loss of genetically- or maternallyinfluenced discriminatory behavior in older larvae. The mechanisms underlying genetic or maternal effects on attachment may act via the external receptors and signal-transduction pathways regulating larval responses. Alternatively, there may be variation in larval 'vigor' or the rate at which cyprids attain metamorphic competence.
\end{abstract}

KEY WORDS: Balanus amphitrite $\cdot$ Barnacle $\cdot$ Larvae $\cdot$ Attachment $\cdot$ Variation $\cdot$ Genetics Resale or republication not permitted without written consent of the publisher

\section{INTRODUCTION}

Settlement, attachment, and metamorphosis of marine invertebrate larvae in response to biochemical and physical cues or neuroactive compounds is extremely variable. All larvae rarely respond to an experimental treatment in the same way (Raimondi \& Keough 1990). Assuming that experimental treatments are applied so as to remove the confounding effects of larval supply or other physical, biological or chemical cues, variation in the proportion of larvae that ultimately attach and metamorphose on a substratum may be due to genetic or environmental influences on the behavior of a larva, including changes with age (Raimondi \& Keough 1990).

Although many sources of variation in attachment and metamorphosis of marine larvae are clear, and in some cases quantified (see Raimondi \& Keough 1990 for review), the effects of genetic, environmental, and

*Corresponding author. E-mail: ritt@duke.edu ontogenetic factors, and their interactions, are poorly understood (Raimondi \& Keough 1990). Metamorphosis of larvae of spirorbid polychaetes in response to algal substrata (Knight-Jones et al. 1971, Doyle 1976, MacKay \& Doyle 1978), gregarious attachment of the bryozoan Bugula neritina (Raimondi \& Keough 1990) and the polychaete Hydroides dianthus (Toonen \& Pawlik 1994), response of cyprids of the barnacle Semibalanus balanoides to crevices (Chabot \& Bourget 1988), and sensitivity of veligers of Phestilla sibogae to a coral inducer (Hadfield 1984), all exhibit genetic variation or differences among populations suggestive of genetic variation. The environment in which larvae develop may affect the ability to detect or respond to a settlement cue. Attachment and metamorphosis of Balanus amphitrite is affected by rearing conditions (Holm 1990a), including the growth phase (Holm 1990b) and type (Clare et al. 1994) of microalgae used to feed developing larvae. Cyprids of B. balanoides (= Semibalanus balanoides, Lucas et al. 1979), B. eburneus (West \& Costlow 1988), and B. amphitrite (Satuito et al. 
1996) require a minimum level of energy reserves or storage proteins to complete metamorphosis. Some larvae lose their ability to discriminate among settlement cues as they age (Knight-Jones 1953, Crisp \& Meadows 1963, Branscomb \& Rittschof 1984, Rittschof et al. 1984, Pechenik et al. 1993).

A model system exhibiting high levels of variability in the proportion of larvae attaching or metamorphosing in response to a cue would be useful for applying a genetic approach to the study of control of larval metamorphosis. Quantification of genetic variation in attachment, including correlations between responses of larvae to natural cues and artificial inducers, could improve our understanding of patterns of recruitment, evolution of settlement behavior, and physiological control of metamorphosis. Genetic correlation between characters is mainly the result of pleiotropy-genes contributing to variation in one trait also affect variation in other traits (Falconer 1981). Measuring the genetic correlations between larval responses to natural cues and artificial inducers that affect signal transduction may aid in identifying the physiological pathways regulating metamorphosis.

Attachment and metamorphosis of cypris larvae of the barnacle Balanus amphitrite (Darwin) are extremely variable. Cyprids of $B$. amphitrite vary in their response to bacterial films (Maki et al. 1988, 1990, Wieczorek et al. 1995, O'Connor \& Richardson 1998), conspecific settlement factors and their mimics (Rittschof et al. 1984, Tegtmeyer \& Rittschof 1989, Holm 1990a, Clare et al. 1994), pharmacological agents (Rittschof et al. 1986, Clare et al. 1992, 1995, Yamamoto et al. 1995, Clare 1996), and surface wettability (Rittschof \& Costlow 1989a,b, Roberts et al. 1991, Gerhart et al. 1992, O'Connor \& Richardson 1994). Evidence suggests that maternal or genetic effects contribute to this variation (Holm 1990a). We tested for genetic or maternal influences on attachment of larvae of $B$. amphitrite in response to control treatments and artificial inducers, and measured correlations between these responses. Our results indicate that variation among families in responses to the control treatments may result from variation in physiological processes proposed to regulate metamorphosis. We raise questions as to the roles of sensation and signal processing, timing of metamorphic competence, and larval 'vigor' in generating variation in settlement.

\section{MATERIALS AND METHODS}

Along the southeastern coast of North America, Balanus amphitrite (Darwin) is found in the mid-intertidal to shallow subtidal zones (Zullo 1979). In the wild, larvae of $B$. amphitrite settle on a number of substrata, including oysters (Crassostrea virginica), the salt marsh cordgrass Spartina alterniflora, rocks, seawalls, and pilings. Adults are iteroparous, simultaneous hermaphrodites. Outcrossing of $B$. amphitrite requires copulation. Fertilized eggs are brooded in the mantle cavity of the maternal parent until release as nauplius larvae.

Collection of maternal parents and larvae. A single barnacle functioning as the paternal parent cannot be crossed with more than 1 maternal parent at a time without introducing potentially confounding effects on characteristics of the larvae due to temporal variation in the conditions under which larvae are reared (Holm 1990a). In order to control for these effects, we collected families of sibling larvae from barnacles found in the field and raised (simultaneously) as many of these families as possible. Because eggs are brooded, we could identify the maternal parent exactly. The identity of the paternal parent(s) could not be determined. We have not observed self-fertilization in Balanus amphitrite raised in isolation in the laboratory. Consequently, we assumed that larvae in a family were potentially a mixture of full- and half-siblings.

We collected Balanus amphitrite from oyster shells and culms of Spartina alterniflora found in the intertidal zone of the Newport River estuary near Beaufort, North Carolina. Oysters and culms of S. alterniflora were chosen such that broods of eggs were unlikely to share a parent.

In the laboratory, broods of well-developed eggs, recognizable by their brown or gray color, were removed from the mantle cavity and placed in labeled plastic cups containing $100 \mathrm{ml}$ of aged, filtered (to $100 \mathrm{kDa}$ ) seawater. Under these conditions, eggs from mature broods hatched spontaneously. When we obtained hatching nauplii from a barnacle on a given substratum, we discarded all the barnacles remaining on that substratum, in order, once again, to insure that no sibships of larvae shared a parent.

Culture of larvae. We estimated the number of larvae released from a brood, then split the larvae into 3 batches of approx. 750 to 1000 nauplii each. Culture of the larvae followed Holm (1990a). A single batch of nauplii was introduced into a quart (0.95 l) mason jar containing $100 \mathrm{ml}$ of a suspension of diatoms (Skeletonema costatum [Grev.] Cleve), $1 \mathrm{ml}$ of antibiotics (penicillin and streptomycin to a final concentration of 54.75 and $91.25 \mathrm{mg} \mathrm{l}^{-1}$, respectively), and enough aged, filtered seawater to bring the total volume of the jar to $400 \mathrm{ml}$. Cultures were kept at 27 to $28^{\circ} \mathrm{C}$ and a 15:9 L:D cycle, and nauplii were fed $100 \mathrm{ml}$ of diatom suspension daily until metamorphosis to the cypris stage, usually $4 \mathrm{~d}$ after initiation of the culture. Under these conditions, all cultures reached a similar point in development (>50\% cyprids) within $12 \mathrm{~h}$ of each other. When more than half of the larvae in a culture 
appeared to have reached the cypris stage, we sieved the contents of the jar and separated cyprids and latestage nauplii. Cyprids were rinsed from the sieves into glass dishes, covered, and stored at $6^{\circ} \mathrm{C}$ until use in experiments 1 and $6 \mathrm{~d}$ later.

Assays for attachment. We tested for permanent attachment of cyprids using the assay described in Branscomb \& Rittschof (1984, see also Rittschof et al. 1992). Larvae were pipetted into polystyrene petri dishes (Falcon 1006, $50 \times 9 \mathrm{~mm}$ ) containing $5 \mathrm{ml}$ of filtered seawater (control treatments) or a solution of the artificial inducer of interest. All assays were conducted at room temperature $\left(20\right.$ to $\left.21^{\circ} \mathrm{C}\right)$ and, when compounds were light-labile, in darkness.

Attachment and metamorphosis of cyprids of Balanus amphitrite are sensitive to the number of larvae in the assay dish; the percentage of larvae attaching increases with increasing density (Clare et al. 1994). Simulations indicate that density-dependence (gregariousness) in settlement can affect the direction of larval response to a given treatment (Gotelli 1990). The response of cyprids of $B$. amphitrite in the attachment assay is density-dependent when the number of larvae is $>20$ (A. S. Clare pers. comm.). We controlled for density-dependent effects on attachment by using 15 to 20 cyprids in each assay. At $6^{\circ} \mathrm{C}$, cyprids of $B$. amphitrite are inactive and can be counted as they are pipetted. We pipetted chilled larvae into the assay dishes in order to facilitate counting. Cyprids became active within minutes of being introduced to the assays.

We evaluated attachment of cyprids after $22 \mathrm{~h}$ exposure to the experimental treatments. Cyprids were considered attached if they were permanently fixed to the surface of the assay dish by their antennules, or if they were fixed and had completed metamorphosis to a small barnacle. The assays were stopped by adding $10 \%$ formalin to each dish. Unattached, attached, and metamorphosed cyprids were counted using a dissecting microscope.

Experimental treatments. We examined attachment of larvae in response to 3 artificial inducers; 3-isobutyl1-methylxanthine (IBMX), phorbol 12,13-dibutyrate (PDB), and 20-hydroxyecdysone (20-HE), and to a control treatment (seawater filtered to $100 \mathrm{kDa}$, filtered seawater [FSW]). All artificial inducers were purchased from Sigma (St. Louis, MO). The control treatment tested for the response of larvae to the surface characteristics of polystyrene. Polystyrene has a low wettability (Gerhart et al. 1992). Settlement of Balanus amphitrite is positively correlated with wettability in the laboratory (Gerhart et al. 1992) and field (Rittschof \& Costlow 1989b, Roberts et al. 1991). IBMX inhibits phosphodiesterases that hydrolyze cyclic AMP (Thompson 1993), while PDB activates protein kinase C (Stabel \& Parker 1993). Cyclic AMP and protein kinase C are believed to play a role in transduction of metamorphic signals in B. amphitrite (Rittschof et al. 1986, Clare et al. 1995, Clare 1996). IBMX induces metamorphosis of B. amphitrite cyprids at concentrations of $10^{-5}$ to $10^{-6} \mathrm{M}$ (Clare et al. 1995). Yamamoto et al. (1995) found that PDB caused B. amphitrite to metamorphose without attaching to the substratum. 20-HE may regulate metamorphosis of cyprids after attachment (Freeman \& Costlow 1983). Larvae of B. amphitrite (Freeman \& Costlow 1983) and B. eburneus (Cheung 1974) exposed to 20-HE also metamorphosed to a small barnacle without attaching to the substratum.

We made stock solutions of the artificial inducers by dissolving the compounds in FSW. PDB and 20-HE did not readily dissolve, so we sonicated the solutions for a few minutes to generate homogeneous dispersions. Stock solutions were diluted to the test concentrations immediately before commencing the experiments. We tested IBMX at $4.5 \times 10^{-6} \mathrm{M}$, PDB at $1 \times 10^{-7} \mathrm{M}$, and 20-HE at $1 \times 10^{-5} \mathrm{M}$. These concentrations generated maximal response in earlier experiments (Clare et al. 1995, McClary et al. unpubl. data).

As larvae may lose the ability to discriminate among settlement cues with age, we were interested in determining how cypris age affected the influence of family (if any) on response to the control and inducer treatments. For this experiment we used a portion of the cyprids from each culture jar to test responses to the treatments 1 and $6 \mathrm{~d}$ after sieving. On Day 1 (1 d old larvae) a subsample of larvae was pipetted into each assay dish, and the remaining larvae returned to storage at $6^{\circ} \mathrm{C}$ until use on Day 6 (6 d old larvae).

Experiments were carried out during the summers of 1993 and 1994. Experiments conducted in 1993 investigated the effects of age and family on attachment, while those conducted in 1994 examined only the effect of family. All larvae for the experiments in 1994 were used $1 \mathrm{~d}$ after sieving.

Statistical analyses. Our analysis for the effect of family on attachment corresponded to a 'Natural progenies' design (Lawrence 1984). In this design, family effects are tested for by 1-way analysis of variance (ANOVA). Assuming no maternal effects, a significant result suggests variation in a character has a genetic basis (Lawrence 1984). We considered the proportion of cyprids attaching in each combination of treatments (for example, attachment of $1 \mathrm{~d}$ old larvae in response to 20-HE) to be separate characters.

The experimental unit in these investigations was the culture jar. For each larval culture we conducted 1 assay per combination of cypris age and inducer treatments. As sibships of larvae were divided across 3 culture jars, for each combination of experimental treatments, each family was represented by 3 replicate 
assays ( 1 assay from each culture). The datum of interest was the proportion of larvae attaching in each assay dish. This proportion was subjected to angular transformation before analysis. We tested these data for homogeneity of variance using the $F_{\max }$ test (Sokal $\&$ Rohlf 1981) or Levene's test (Levene 1960). Depending on the result, the data were analyzed using either parametric or non-parametric methods. The $F_{\max }$ tests were calculated manually; all other analyses were carried out using SAS (SAS Institute Inc. 1989).

Genetic correlations are usually calculated between different characters measured on the same individual. The same character (for example, the proportion of larvae attaching) measured in 2 different environments (for example, control vs IBMX treatments) can also be treated as 2 different characters for the purpose of computing genetic correlations (Falconer 1981). Calculation of such correlations is not straightforward, as the measurements cannot be made on the same individual (Via 1984). In such cases, the genetic correlation can be approximated by the correlation of family means (Via 1984). We calculated Pearson productmoment correlations between larval responses that exhibited significant family effects, using the family means of the residuals from a 1-way ANOVA for the effect of 'trial' on attachment (see 'Results'). All correlations were calculated using SAS (SAS Institute Inc. 1989). These correlations potentially include components relating to maternal as well as genetic effects, and thus should be interpreted only as 'broad sense' estimates of the true genetic correlation (Via 1984).

\section{RESULTS}

In 1993 we examined the effects of cypris age and family on attachment of Balanus amphitrite in response to the control treatment and to IBMX. The experiment was conducted in 2 trials; the first comprised offspring of 15 maternal parents, the second 13, for a total of 28 families. The mean number of cyprids used in each assay was 15.5 ( $\mathrm{SD}=2.19$, range 9 to 32 ).

Attachment of cyprids was strongly affected by trial, cypris age and inducer treatment (control vs IBMX) (Table 1). There were no significant interactions between or among these main effects. This analysis assumed no effect of the maternal parents or interactions including the maternal parents on attachment. This assumption was necessary because of heteroscedasticity at the level of the families (see below). Given that we detected an effect of family (see below), the assumption should have resulted in inflation of the error mean square in the ANOVA. This had no effect on our ability to detect differences in attachment between trials, ages of larvae, or inducer treatments
Table 1. Balanus amphitrite. Results of analysis of trial, cypris age, and inducer treatments on proportion of cyprids attaching. All tests used Type III sums-of-squares in calculations. Error MS served as denominator for all $F$ statistics. p: probability $>F_{,}^{*} \mathrm{p}<0.05$

\begin{tabular}{|lrrrl|}
\hline Source & df & \multicolumn{1}{c}{ MS } & $F$ & $\mathrm{p}$ \\
\hline Trial (T) & 1 & 2101.69 & 9.16 & $0.0027^{*}$ \\
Cypris age (A) & 1 & 23162.16 & 100.90 & $0.0001^{*}$ \\
Inducer (I) & 1 & 18738.60 & 81.63 & $0.0001^{*}$ \\
$\mathrm{~T} \times \mathrm{A}$ & 1 & 124.91 & 0.54 & 0.46 \\
$\mathrm{~T} \times \mathrm{I}$ & 1 & 697.65 & 3.04 & 0.08 \\
$\mathrm{~A} \times \mathrm{I}$ & 1 & 821.17 & 3.58 & 0.06 \\
$\mathrm{~T} \times \mathrm{A} \times \mathrm{I}$ & 1 & 65.23 & 0.28 & 0.59 \\
Error & 298 & 229.56 & & \\
& & & & \\
\hline
\end{tabular}

(Table 1). Interactions between trial and inducer, and cypris age and inducer, may have been significant in the full analysis, but inspection of the means (Fig. 1) suggested that such interactions would not compromise our interpretation of the main effects. The proportion of cyprids attaching in the assays was slightly higher in the 2nd than in the 1st trial, was substantially higher in the IBMX than in the control treatment, and increased as larvae aged from 1 to $6 \mathrm{~d}$ (Fig. 1).

The data were heteroscedastic at the level of the maternal parents due to one or a few families (depending on age and inducer treatment) exhibiting no variance in the proportion of cyprids attaching. Given this result, our analysis for the effect of family on attach-

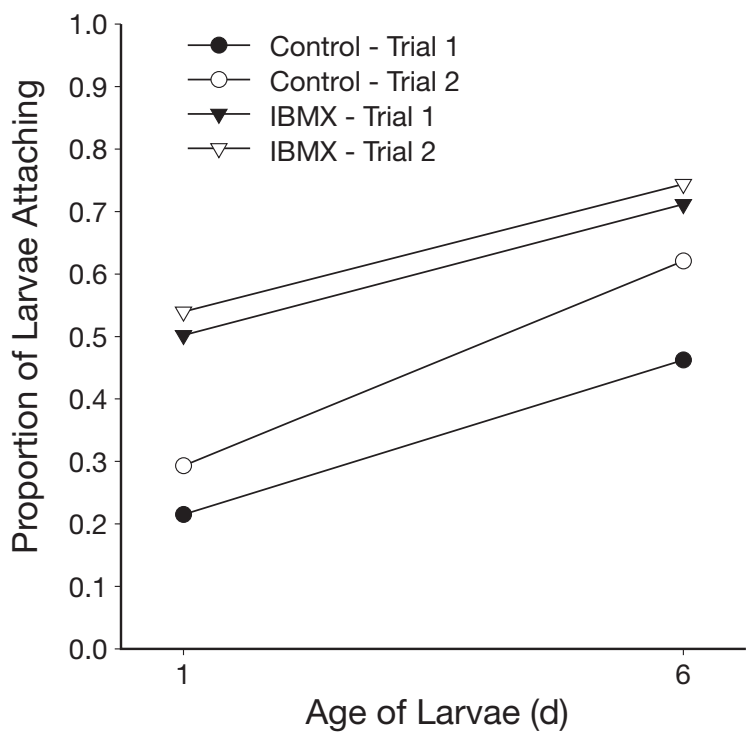

Fig. 1. Balanus amphitrite. Effects of trial, age of larvae (days after metamorphosis to cypris stage), and inducer treatment (control vs IBMX) on proportion of cyprids attaching in $22 \mathrm{~h}$ settlement assays. Data are for experiments conducted in 1993. Datapoints represent means of 37 to 40 replicates; error bars omitted for clarity 
ment followed 2 steps. First, we subjected the data to a 1-way (parametric) ANOVA, with trial as the main effect, and saved the resulting residuals. In all 4 cases (age and inducer treatment combinations), variances were homogeneous between trials. This procedure removed any variation in attachment due to 'trial' (for example, any effect on attachment of variation in culture conditions over time [Holm 1990a,b]). For each combination of inducer and larval age treatment, the remaining variation should have been due to whatever influence family may have had on attachment plus random variation among replicate assays within a family. We then conducted a Kruskal-Wallis test ( $H$ statistic) using the residuals to determine if there were significant differences among the families and, therefore, significant genetic or maternal effects, in the proportion of cyprids attaching.

Family had a significant effect only on the proportion of $1 \mathrm{~d}$ old larvae attaching in the control treatment (Fig. 2, $H=42.16$, df $=27, \mathrm{p}=0.032$ ). There were no significant effects of family for response of $6 \mathrm{~d}$ old cyprids to the control treatment, nor for response of 1 and 6 d old larvae to the IBMX treatment (Fig. 2).

As there was no effect of family on attachment of $6 \mathrm{~d}$ old cyprids, we eliminated the age treatment from the experiment conducted in 1994; all assays used 1 d-old larvae. We tested for response to the artificial inducers 20-HE and PDB as well as to IBMX. In addition, the control treatment was replicated; for each culture of larvae we conducted 2 assays for attachment in FSW. The experiment consisted of 3 trials, the first 2 includ-
Table 2. Balanus amphitrite. Results of analysis of trial and inducer treatments on proportion of cyprids attaching. All tests used Type III sums-of-squares in calculations. Error MS served as denominator for all $F$ statistics. p: probability $>F$; ${ }^{*} \mathrm{p}<0.05$

\begin{tabular}{|lrrrl|}
\hline Source & df & \multicolumn{1}{c}{ MS } & \multicolumn{1}{c|}{$F$} & \multicolumn{1}{c|}{$\mathrm{p}$} \\
\hline Trial (T) & 2 & 3383.32 & 15.82 & $0.0001^{*}$ \\
Inducer (I) & 4 & 28279.42 & 132.21 & $0.0001^{*}$ \\
T $\times$ I & 8 & 258.85 & 1.21 & 0.29 \\
Error & 659 & 213.90 & & \\
\hline
\end{tabular}

ing the offspring of 16 maternal parents, the third 13, giving a total of 45 families. The mean number of cyprids used in each assay was $14.9(\mathrm{SD}=1.21$, range 11 to 20$)$.

Attachment of larvae was significantly different among the trial and inducer treatments, and there was no trial $\times$ inducer interaction (Table 2 ). Due once again to heteroscedasticity at the level of families, for this analysis we assumed no effect of maternal parent or any interaction including the maternal parent on the attachment of cyprids. This assumption did not affect our ability to detect differences among the trials or inducer treatments (Table 2). The 2 control treatments generated similar levels of attachment (Fig. 3). Attachment of cyprids in response to 20-HE was significantly higher than that for the controls (Fig. 3). The proportion of larvae attaching was not different between the IBMX and PDB treatments. The response to these com-
Fig. 2. Balanus amphitrite. Mean residuals for proportion of larvae attaching in response to either control or IBMX treatments, for each family. Data are for experiments conducted in 1993. Residuals for each replicate assay were generated by removing effect of trial in 1-way ANOVA; remaining variation is due to differences among families and among replicate assays within families. Points represent means of 2 to 3 assays; error bars are standard deviations. $H$ : value of KruskalWallis test statistic for differences among families; df: degrees of freedom; p: probability $>H_{i}{ }^{*} \mathrm{p}<0.05$
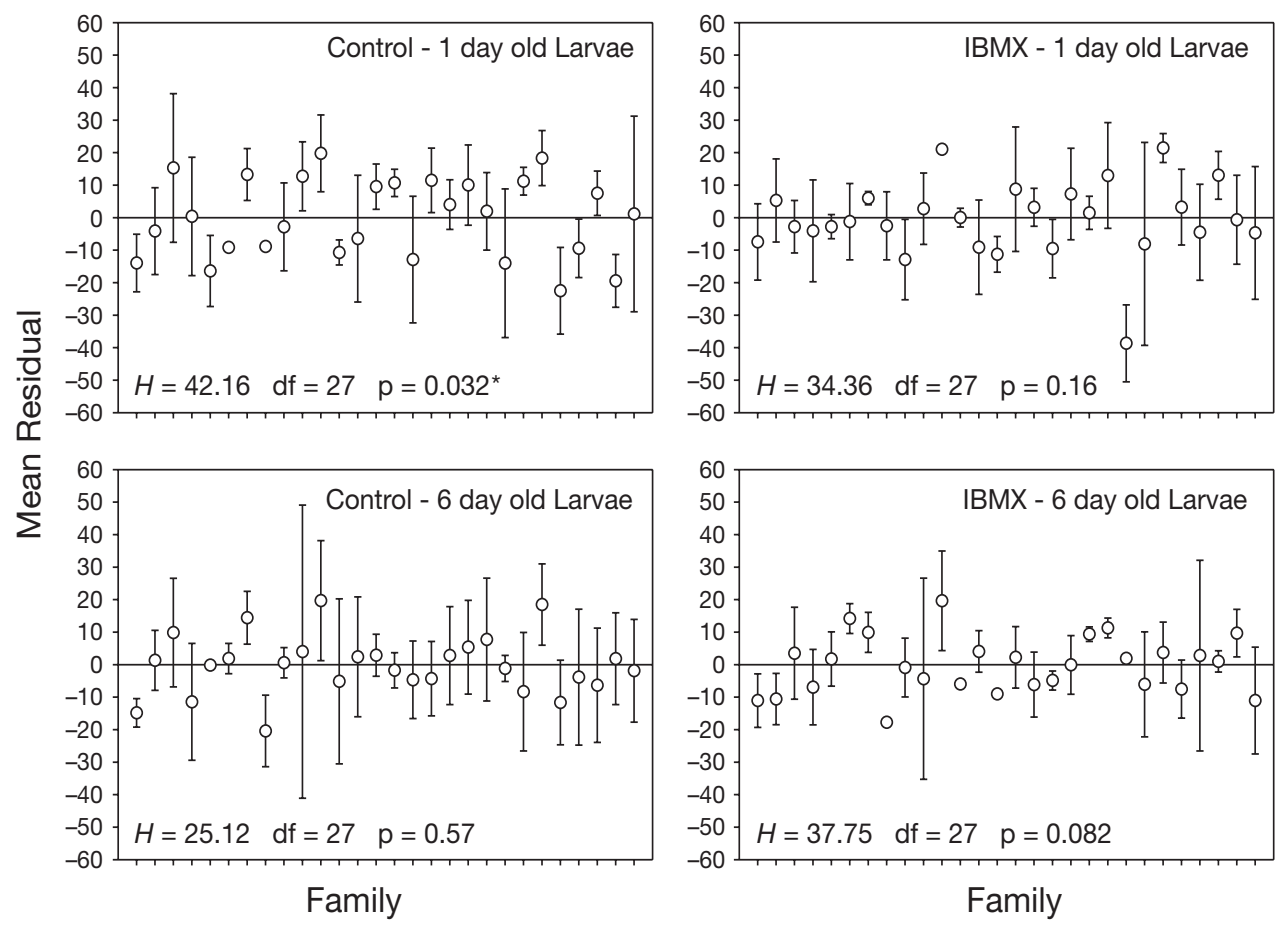

Family 


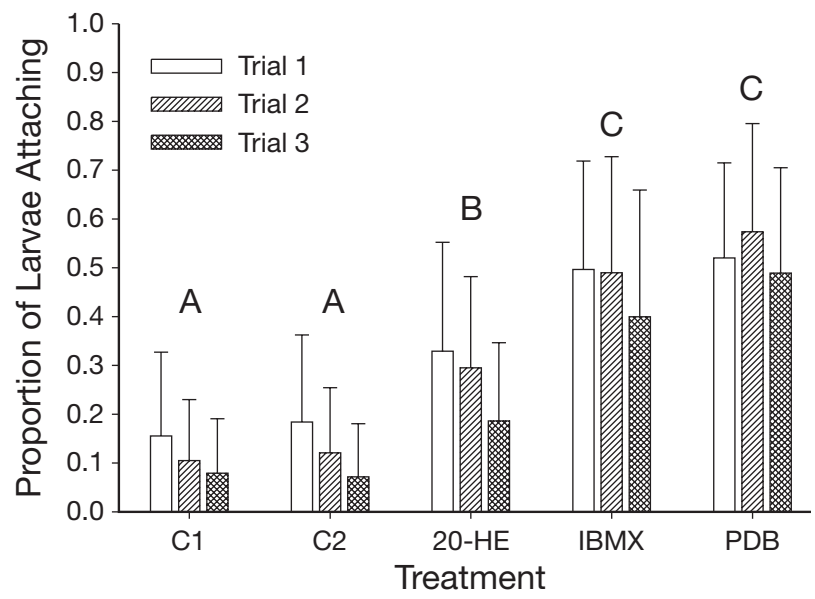

Fig. 3. Balanus amphitrite. Effects of trial and inducer treatment on proportion of cyprids attaching in $22 \mathrm{~h}$ settlement assays. Data are for experiments conducted in 1994. Bars represent means of 38 to 48 replicates, error bars are standard deviations. Inducer treatments with same letter were not significantly different from each other (Tukey's Studentized range test, $\alpha=0.05$ ) pounds, however, was significantly greater than that we observed for the 2 controls and 20-HE (Fig. 3). In contrast to previous results with 20-HE (Cheung 1974, Freeman \& Costlow 1983) and PDB (Yamamoto et al. 1995), no cyprids metamorphosed in response to these compounds without first attaching to the surface of the assay dish.

The data from the 1994 experiment were also heteroscedastic at the level of the maternal parents. We followed the same procedures in analyzing these data for family effects as we had for the 1993 experiment. The effect of family was significant for some inducer treatments but not others (Fig. 4). The replicated control treatments gave contradictory results. There was no significant effect of family for response in the 1st replicate (Control 1, $H=57.1$, df $=44, \mathrm{p}=0.089$ ), but a strong effect on attachment in the 2nd replicate (Control 2, $H=67.4$, df $=44, \mathrm{p}=0.013$ ). In contrast to the 1993 results, we also observed strong family effects for the IBMX treatment $(H=71.7, \mathrm{df}=44, \mathrm{p}=0.005)$. Family had a significant influence on attachment of
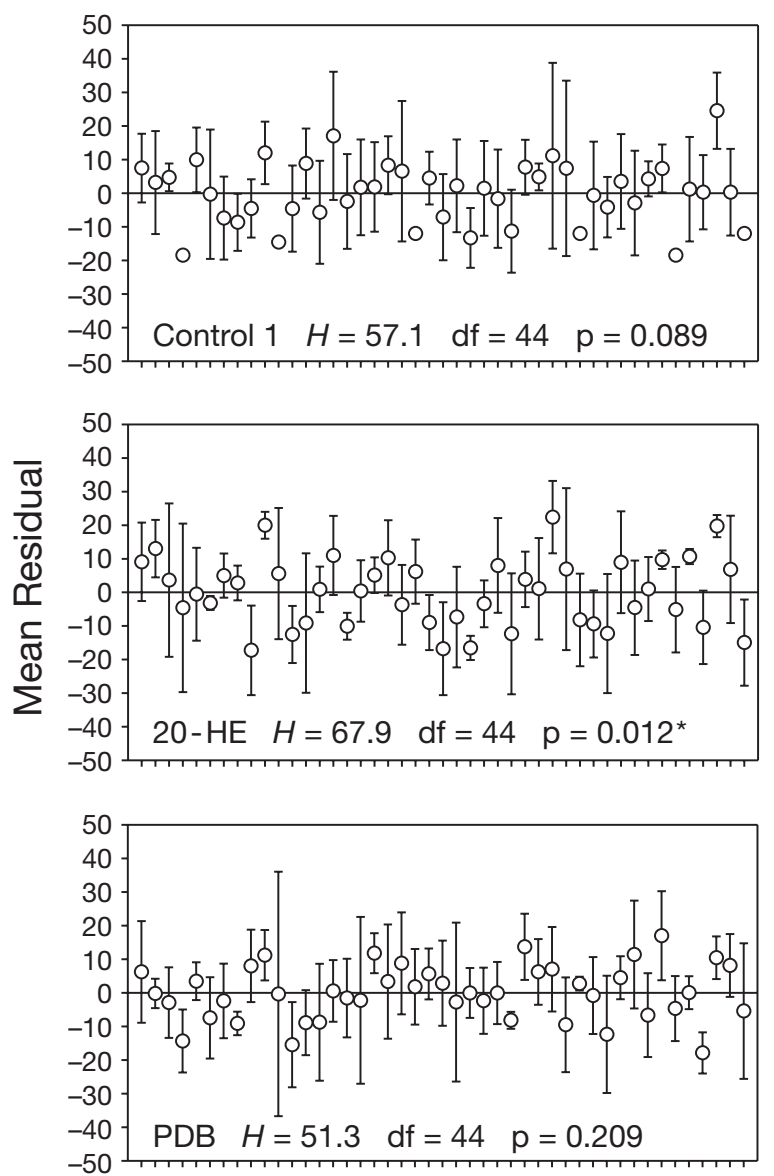

Family
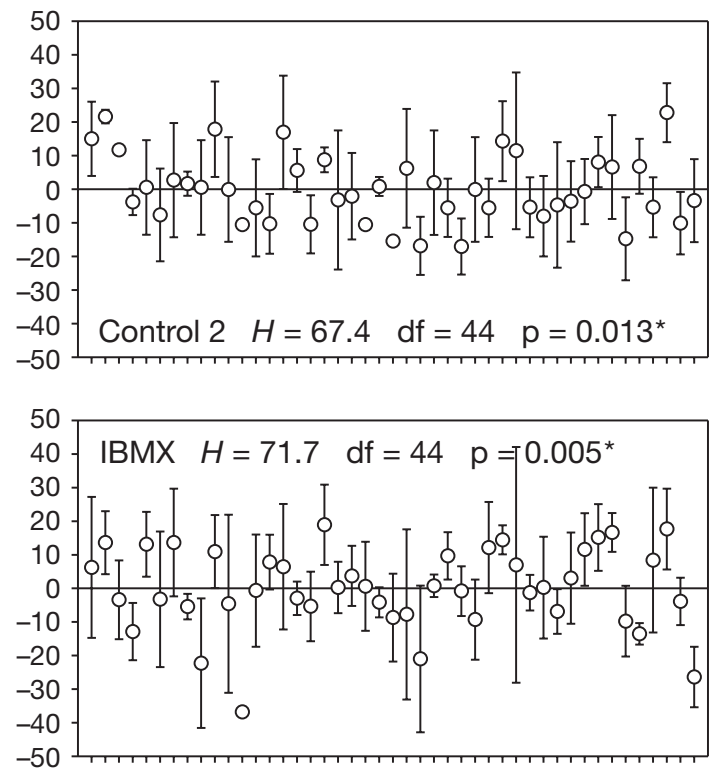

Family

Fig. 4. Balanus amphitrite. Mean residuals for proportion of larvae attaching in response to each inducer treatment, for each family. Data are for experiments conducted in 1994. Residuals for each replicate assay were generated by removing effect of trial in 1-way ANOVA; remaining variation is due to differences among families and among replicate assays within families. Points represent means of 2 to 3 assays, error bars are standard deviations. $H$ : value of KruskalWallis test statistic for differences among families; df: degrees of freedom; p: probability $>H_{;}{ }^{*} \mathrm{p}<0.05$ 

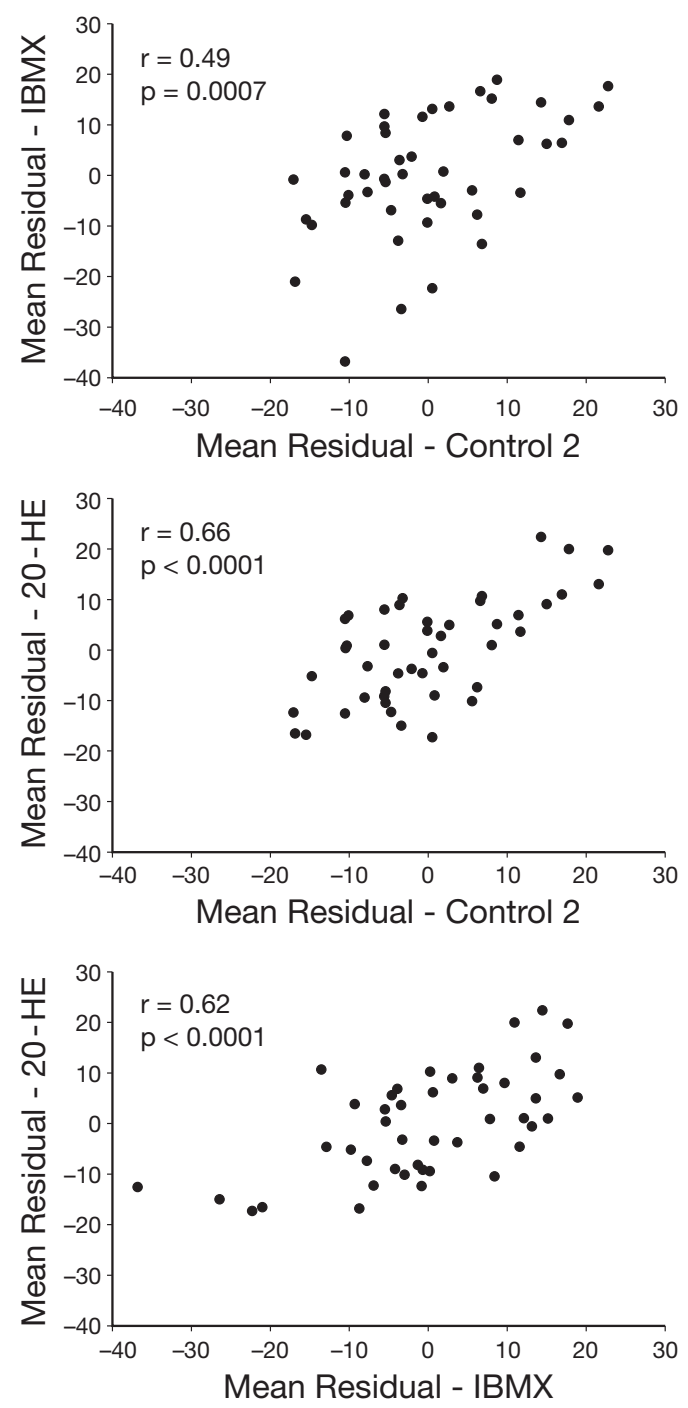

Fig. 5. Balanus amphitrite. Correlations between mean residuals (by family) for each inducer treatment for which effect of family was significant. Data are for experiments conducted in 1994. r: Pearson's product-moment correlation; p: probability $>|\mathrm{r}|$

cyprids in the assays with 20-HE $(H=67.9, \mathrm{df}=44$, $\mathrm{p}=0.012)$, but not in the assays with $\operatorname{PDB}(H=51.3$, $\mathrm{df}=44, \mathrm{p}=0.21$ ).

Pearson's product-moment correlations between family means of the residuals were significant and positive for all treatments for which maternal parent had a significant effect on attachment (Control 2, 20-HE, IBMX; Fig. 5).

\section{DISCUSSION}

We observed strong variation in the proportion of cyprids of Balanus amphitrite permanently attaching in response to the control and inducer treatments. Ignoring the effects of cypris age, variation occurred at 5 levels: (1) among larvae within individual assays; (2) among replicate assays within families; (3) among families; (4) between or among trials within experiments; (5) between experiments.

Within most assays, some larvae responded by attaching while others did not. This sort of variation is expected if attachment is the result of a number of complex physiological processes that are influenced to differing degrees by genetic and environmental effects. Under these assumptions the propensity of a cyprid to attach (liability, in the sense of threshold characters [Falconer 1981]) should be normally distributed across larvae in an assay. Those larvae that express some liability over a certain threshold will attach.

Variation among replicate assays within a family probably arises from differences in environmental conditions among larval cultures. Holm (1990b) found significant effects of the larval rearing environment on attachment of cyprids of Balanus amphitrite in flow. Variation among assays may be the result of environmentally-induced plasticity in attachment and metamorphosis. Alternatively, there may be selection during the rearing process for larvae expressing a different propensity to attach. Mallet et al. (1985) and Beaumont et al. (1988, 1990) observed genotypedependent mortality in cultures of larval Mytilus edulis. Not all larvae survived our rearing process, so we cannot eliminate the selection hypothesis.

Variation among families in attachment was significant for $1 \mathrm{~d}$ old larvae tested against the control treatment in 1993 (Fig. 2), and for cyprids responding to the second control, 20-HE, and IBMX in the experiments conducted in 1994 (Fig. 4). These results indicate that genetic effects (including additive and non-additive components) or maternal effects can influence the response of a larva to a given surface or inducer. Significant correlations between responses to 20-HE, IBMX, and the second control (Fig. 5) suggest that some portion of the variation in attachment in these treatments is produced by the same genetic or maternal effects.

The magnitude of genetic or maternal effects in a given experiment is a function of the population for which the character of interest is measured, and the particular environmental conditions under which offspring are bred, reared and tested (Falconer 1981). The significant variation we observed among trials in 1993 (Table 1, Fig. 1) and 1994 (Table 2, Fig. 3) may be due to subtle changes in the rearing environment from trial to trial, or to differences among the populations of barnacles serving as parents. Variation between the 1993 and 1994 experiments in the effect of family on attachment in response to IBMX may also be explained in this way. 


\section{Interpreting family effects}

\section{Caveats}

We obtained conflicting results for responses of larvae to the IBMX treatment in 1993 and 1994 (see preceding section) and for responses to the 2 control treatments in the 1994 experiment. Therefore, the interpretation we offer below of variation in attachment among families must be viewed cautiously. In the experiment conducted in 1994, there was no effect of family on cypris response to Control 1, and a highly significant effect for Control 2 (Fig. 4). The only difference between these 2 treatments was in the order in which they were loaded with larvae. Cyprids were introduced to Control 2 approx. 1 to 2 min after Control 1. It is difficult to see how this difference, in an assay that lasted $22 \mathrm{~h}$, could account for the result we observed. Instead, we believe these contrasting results are a function of environmental variation among larval cultures within a family, combined with the low level of replication (3 assays of a given treatment for each family). The variation we observed between the 1993 and 1994 experiments in the response of $1 \mathrm{~d}$ old cyprids to the IBMX treatment may also be due in part to these effects.

Our explanation of the role of signal-transduction pathways and hormonal regulation must also be viewed with caution. Pawlik (1990) suggested that assays for the effects of artificial inducers, such as IBMX, on whole larvae were not suitable for identifying the physiological pathways regulating metamorphosis, because of the multiple effects these compounds have on cells and tissues.

\section{Sensation, competence or 'vigor'?}

Attachment represents the culmination of a complex series of events. The specific mechanisms by which genetic or maternal environmental effects influence the process are not known. Hadfield (1984) identified 2 scenarios under which variation in metamorphosis could be generated. Variation among families in the response of cyprids to a treatment might arise from variation in the sensory apparatus and signal-transduction pathways mediating attachment and metamorphosis. Alternatively, all larvae may detect and respond to the same metamorphic signals in the same way, but there may be variation among families in the point in time at which this ability is attained, or whether it is attained at all. In the first scenario, all larvae would be capable of settling when presented with an appropriate cue, but there are differences among larvae in which cues are sufficient to trigger the larval nervous system. In the second case, variation in attachment results from differences among individual larvae and families of larvae in their rate of development under the rearing conditions employed (Hadfield 1984), or in their fitness or 'vigor' (Fry 1993).

If all cyprids in our experiments were competent to metamorphose, then the significant variation among families we observed for the control treatments (Figs. 2 \& 4) may have been due to genetic or maternal effects on response to surface characteristics (for example, wettability) of the petri dishes. In the 1994 experiments, family means were significantly correlated for the attachment of cyprids in the 20-HE and IBMX treatments (Fig. 5). This result suggests that variation in attachment in the controls was partly a function of variation in the physiological pathways that are affected by 20-HE and IBMX. These pathways are signal transduction by the adenylate cyclase/cyclic AMP (AC/cAMP) pathway (Thompson 1993, Clare et al. 1995, Clare 1996) and, presumably, hormonal regulation of the attachment and metamorphosis process (Freeman \& Costlow 1983). There was no variation among families for attachment in the PDB treatments (Fig. 4). PDB affects signal transduction by the phosphatidylinositol/diacylglycerol/protein kinase C (PI/DAG/PKC) pathway (Stabel \& Parker 1993). This compound may affect attachment at a point in the metamorphic pathway after the point at which variation in external receptors, the AC/cAMP pathway, or hormonal regulation, is expressed. Alternatively, PDB may act via a completely unrelated mechanism.

If our results were due to genetic or maternal environmental effects on the timing of acquisition of metamorphic competence, or to larval 'vigor', then we should have observed significant effects of family for responses to all treatments for which cyprids exhibited some variation in attachment, and positive correlations between these responses (Fry 1993). We observed no family effects for attachment in response to PDB (Fig. 4), suggesting that interpretation of our results on the basis of variation in larval sensory structures and regulatory pathways (see preceding paragraph) may be appropriate.

Without an independent estimation of metamorphic competence or larval 'vigor' it is not possible for us to distinguish between these alternatives. Larvae of marine invertebrates metamorphose at different times in response to different inducers, both artificial and natural (Pechenik \& Gee 1993, Pechenik et al. 1995, Pechenik \& Qian 1998). If synthesis or up-regulation of external receptors (Trapido-Rosenthal \& Morse 1986) is the final step in the acquisition of competence, then artificial inducers, such as 20-HE and IBMX (which are hypothesized to stimulate metamorphosis after bypassing a portion of the receptor-mediated pathway regu- 
lating settlement) do not provide any information as to whether larvae are competent to respond to natural biochemical or physical cues (Pechenik et al. 1995). Estimates of the proportion of larvae that are competent to attach and metamorphose can only be obtained by exposing larvae to natural cues.

\section{Ontogenetic effects}

Variation among families in attachment in the control treatment decreased as the cyprids aged from 1 to $6 \mathrm{~d}$ old (Fig. 2). This may have been due to the loss with age of genetically or maternally influenced discriminatory ability. We would have expected a similar result, however, if families of larvae varied in the age at which they became competent to metamorphose, and if after $6 \mathrm{~d}$ all larvae, regardless of family, had reached the same physiological state. Both interpretations are difficult to reconcile with the observation that attachment of $6 \mathrm{~d}$ old larvae in the control treatment was significantly less than that for the IBMX treatment, and well below $100 \%$ (Fig. 1).

\section{Implications for bioassays}

Whatever the mechanistic basis for variation in attachment, it is clear that responses of cyprids of Balanus amphitrite can be strongly affected by, at a minimum, their maternal parent. This result has important implications for the conduct and interpretation of settlement bioassays, whether for the examination of potentially inductive compounds or cues, or substances designed to inhibit metamorphosis. If the response of larvae to a particular treatment expresses some genetic or maternal environmental variation, and is not correlated with competence or 'vigor', then results from single experiments, even if the subject larvae originated from mass spawnings or releases, may not be general. The number of parents contributing to a mass spawning or release of larvae may be unknown, fertilization of spawned gametes may be non-random, and rearing procedures may generate selective mortality during development. These processes could all result in larvae that represent a reduced set of phenotypes for response to the treatments of interest. The problem can be avoided by replicating experiments using larvae from a different broodstock for each replicate, or by designing experiments that explicitly account for genetic or maternal effects on metamorphosis.

Acknowledgements. This research was funded by a grant from the Office of Naval Research (No. N00014-92-J-1516). We thank A. Clare and the anonymous reviewers for valuable comments on preliminary drafts of the manuscript.

\section{LITERATURE CITED}

Beaumont AR, Beveridge CM, Barnet EA, Budd MD, SmythChamosa M (1988) Genetic studies of laboratory-reared Mytilus edulis. I. Genotype specific selection in relation to salinity. Heredity 61:389-400

Beaumont AR, Beveridge CM, Barnet EA, Budd MD (1990) Genetic studies of laboratory-reared Mytilus edulis. III. Scored loci act as markers for genotype-specific mortalities which are unrelated to temperature. Mar Biol 106: $227-233$

Branscomb ES, Rittschof D (1984) An investigation of low frequency sound waves as a means of inhibiting barnacle settlement. J Exp Mar Biol Ecol 79:149-154

Chabot R, Bourget E (1988) Influence of substratum heterogeneity and settled barnacle density on the settlement of cypris larvae. Mar Biol 97:45-56

Cheung PJ (1974) The effect of ecdysterone on cyprids of Balanus eburneus Gould. J Exp Mar Biol Ecol 15:223-229

Clare AS (1996) Signal transduction in barnacle settlement: calcium revisited. Biofouling 10:141-159

Clare AS, Freet RK, McClary M Jr (1994) On the antennular secretion of the cyprid of Balanus amphitrite amphitrite, and its role as a settlement pheromone. J Mar Biol Assoc UK 74:243-250

Clare AS, Rittschof D, Costlow JD Jr (1992) Effects of the nonsteroidal ecdysone mimic RH 5849 on larval crustaceans. J Exp Zool 262:436-440

Clare AS, Thomas RF, Rittschof D (1995) Evidence for the involvement of cyclic AMP in the pheromonal modulation of barnacle settlement. J Exp Biol 198:655-664

Crisp DJ, Meadows PS (1963) Adsorbed layers: the stimulus to settlement in barnacles. Proc R Soc Lond Ser B 158:364-387

Doyle RW (1976) Analysis of habitat loyalty and habitat preference in the settlement behavior of planktonic marine larvae. Am Nat 110:719-730

Falconer DS (1981) Introduction to quantitative genetics. Longman Inc, New York

Freeman JA, Costlow JD (1983) The cyprid molt cycle and its hormonal control in the barnacle Balanus amphitrite. J Crustac Biol 3:173-182

Fry JD (1993) The 'general vigor' problem: can antagonistic pleiotropy be detected when genetic covariances are positive? Evolution 47:327-333

Gerhart DJ, Rittschof D, Hooper IR, Eisenman K, Meyer AE, Baier RE, Young C (1992) Rapid and inexpensive quantification of the combined polar components of surface wettability: application to biofouling. Biofouling 5:251-259

Gotelli NJ (1990) Stochastic models of gregarious larval settlement. Ophelia 32:95-108

Hadfield MG (1984) Settlement requirements of molluscan larvae: new data on chemical and genetic roles. Aquaculture 39:283-298

Holm ER (1990a) Attachment behavior in the barnacle Balanus amphitrite amphitrite (Darwin): genetic and environmental effects. J Exp Mar Biol Ecol 135:85-98

Holm ER (1990b) Settlement site choice in the barnacle Balanus amphitrite: demographic and evolutionary consequences. PhD dissertation. Duke University, Durham, NC

Knight-Jones EW (1953) Decreased discrimination during setting after prolonged planktonic life in larvae of Spirorbis borealis (Serpulidae). J Mar Biol Assoc UK 32:337-345

Knight-Jones EW, Bailey JH, Isaac MJ (1971) Choice of algae by larvae of Spirorbis, particularly of Spirorbis spirorbis. In: Crisp DJ (ed) 4th European Marine Biology Symposium. Cambridge University Press, Cambridge, p 89-104 
Lawrence MJ (1984) The genetical analysis of ecological traits. In: Shorrocks B (ed) Evolutionary ecology. Blackwell, Oxford, p 27-63

Levene $H$ (1960) Robust tests for the equality of variance. In: Olkin I (ed) Contributions to probability and statistics. Stanford University Press, Palo Alto, p 278-292

Lucas MI, Walker G, Holland DL, Crisp DJ (1979) An energy budget for the free-swimming and metamorphosing larvae of Balanus balanoides (Crustacea: Cirripedia). Mar Biol 55:221-229

MacKay TFC, Doyle RW (1978) An ecological genetic analysis of the settling behaviour of a marine polychaete. I. Probability of settlement and gregarious behaviour. Heredity 40:1-12

Maki JS, Rittschof D, Costlow JD, Mitchell R (1988) Inhibition of attachment of larval barnacles, Balanus amphitrite, by bacterial surface films. Mar Biol 97:199-206

Maki JS, Rittschof D, Samuelsson MO, Szewzyk U, Yule AB, Kjelleberg S, Costlow JD, Mitchell R (1990) Effect of marine bacteria and their exopolymers on the attachment of barnacle cypris larvae. Bull Mar Sci 46:499-511

Mallet AL, Zouros E, Gartner-Kepkay KE, Freeman KR, Dickie LM (1985) Larval viability and heterozygote deficiency in populations of marine bivalves: evidence from pair matings of mussels. Mar Biol 87:165-172

O'Connor NJ, Richardson DL (1994) Comparative attachment of barnacle cyprids (Balanus amphitrite Darwin, 1854; $B$. improvisus Darwin, 1854; \& B. eburneus Gould, 1841) to polystyrene and glass substrata. J Exp Mar Biol Ecol 183: 213-225

O'Connor NJ, Richardson DL (1998) Attachment of barnacle (Balanus amphitrite Darwin) larvae: responses to bacterial films and extracellular materials. J Exp Mar Biol Ecol 226: 115-129

Pawlik JR (1990) Natural and artificial induction of metamorphosis of Phragmatopoma lapidosa californica (Polychaeta: Sabellariidae), with a critical look at the effects of bioactive compounds on marine invertebrate larvae. Bull Mar Sci 46:512-536

Pechenik JA, Gee CC (1993) Onset of metamorphic competence in larvae of the gastropod Crepidula fornicata (L.), judged by a natural and an artificial cue. J Exp Mar Biol Ecol 167:59-72

Pechenik JA, Qian PY (1998) Onset and maintenance of metamorphic competence in the marine polychaete Hydroides elegans Haswell in response to three chemical cues. J Exp Mar Biol Ecol 226:51-74

Pechenik JA, Rittschof D, Schmidt AR (1993) Influence of delayed metamorphosis on survival and growth of juvenile barnacles Balanus amphitrite. Mar Biol 115:287-294

Pechenik JA, Hadfield MG, Eyster LS (1995) Assessing whether larvae of the opisthobranch gastropod Phestilla sibogae Bergh become responsive to three chemical cues at the same age. J Exp Mar Biol Ecol 191:1-17

Raimondi PT, Keough MJ (1990) Behavioural variability in marine larvae. Aust J Ecol 15:427-437

Rittschof D, Costlow JD (1989a) Surface determination of macroinvertebrate larval settlement. In: Stycynska-Jurewicz E (ed) Proceedings of the 21st European Marine Biology Symposium. Polish Academy of Sciences, Institute of Oceanology, Gdansk, p 155-163

Editorial responsibility: John Austin (Assistant Editor), Oldendorf/Luhe, Germany
Rittschof D, Costlow JD (1989b) Bryozoan and barnacle settlement in relation to initial surface wettability: a comparison of laboratory and field studies. Sci Mar 53:411-416

Rittschof D, Branscomb ES, Costlow JD (1984) Settlement and behavior in relation to flow and surface in larval barnacles, Balanus amphitrite Darwin. J Exp Mar Biol Ecol 82:131-146

Rittschof D, Maki J, Mitchell R, Costlow JD (1986) Ion and neuropharmacological studies of barnacle settlement. Neth J Sea Res 20:269-275

Rittschof D, Clare AS, Gerhart DJ, Avelin M Sr, Bonaventura $\mathrm{J}$ (1992) Barnacle in vitro assays for biologically active substances: toxicity and settlement inhibition assays using mass cultured Balanus amphitrite amphitrite Darwin. Biofouling 6:115-122

Roberts D, Rittschof D, Holm E, Schmidt AR (1991) Factors influencing initial larval settlement: temporal, spatial and surface molecular components. J Exp Mar Biol Ecol 150: 203-221

SAS Institute Inc. (1989) SAS/STAT user's guide. Version 6, 4th edn. SAS Institute, Cary, NC

Satuito CG, Shimizu K, Natoyama K, Yamazaki M, Fusetani N (1996) Age-related settlement success by cyprids of the barnacle Balanus amphitrite, with special reference to consumption of cyprid storage protein. Mar Biol 127:125-130

Sokal RR, Rohlf FJ (1981) Biometry. The principles and practice of statistics in biological research, 2nd edn. Freeman \& Co, New York

Stabel S, Parker PJ (1993) Protein kinase C. In: Taylor CW (ed) Intracellular messengers. Pergamon Press, Oxford, p 167-198

Tegtmeyer K, Rittschof D (1989) Synthetic peptide analogs to barnacle settlement pheromone. Peptides 9:1403-1406

Thompson WJ (1993) Cyclic nucleotide phosphodiesterases: pharmacology, biochemistry and function. In: Taylor CW (ed) Intracellular messengers. Pergamon Press, Oxford, p 287-313

Toonen RJ, Pawlik JR (1994) Foundations of gregariousness. Nature 370:511-512

Trapido-Rosenthal HG, Morse DE (1986) Regulation of receptor-mediated settlement and metamorphosis in larvae of a gastropod mollusc (Haliotis rufescens). Bull Mar Sci 39:383-392

Via S (1984) The quantitative genetics of polyphagy in an insect herbivore. II. Genetic correlations in larval performance within and among host plants. Evolution 38: 896-905

West TL, Costlow JD (1988) Determinants of the larval molting pattern of the crustacean Balanus eburneus Gould (Cirripedia: Thoracica). J Exp Zool 248:33-44

Wieczorek SK, Clare AS, Todd CD (1995) Inhibitory and facilitatory effects of microbial films on settlement of Balanus amphitrite amphitrite larvae. Mar Ecol Prog Ser 119: 221-228

Yamamoto H, Tachibana A, Matsumura K, Fusetani N (1995) Protein kinase C (PKC) signal transduction system involved in larval metamorphosis of the barnacle, Balanus amphitrite. Zool Sci 12:391-396

Zullo VA (1979) Marine flora and fauna of the northeastern United States. Arthropoda: Cirripedia. NOAA Natl Mar Fish Serv Tech Rep Circ 425:1-29

Submitted: July 29, 1999; Accepted: February 8, 2000 Proofs received from author(s): July 24, 2000 